\title{
EFEKTIFITAS PIJAT OKETANI TERHADAP BENDUNGAN ASI PADA IBU POSTPARTUM DI RSB.MASYITA MAKASSAR
}

\author{
Fatma Jama ${ }^{1)}$ Suhermi.S ${ }^{2)}$ \\ ${ }^{1}$ Fakultas Kesehatan Masyarakat, Universitas, Muslim Indonesia \\ email: fatma.jama@umi.ac.id \\ ${ }^{2}$ Fakultas Kesehatan Masyarakat, Universitas, Muslim Indonesia \\ email: suhermisudirman88@gmail.com
}

\begin{abstract}
Exclusive breastfeeding is influenced by several factors, including breast milk does not immediately come out on the first day after childbirth, the mother feels the milk comes out a little, the difficulty of the baby in sucking, the condition of putting breast milk and the promotion of breast milk substitute. The conditions in the field indicate that the success of early breastfeeding is also influenced by the condition of the mother and baby. Working mothers and low level of mother and family's knowledges regard the benefits and appropriate ways of breastfeeding.

The application of oketani massage to post partum mothers is still rarely done because usually mothers only do regular breast massage. Oketani massage is a management skill to overcome the problem of lactation such as inadequate breast milk production, breast swelling, oketani massage will cause the breasts to become soft, supple and the areola will become elastic, the lactiferous duct and the nipple also become elastic.

The research design used was quasi experimental with a pre-test and post-test design. This study only used one group, namely the intervention group without the control group to see the effectiveness of the ASI dam in the intervention group. The sampling technique used was consecutive sampling, the sample in this study were 15 postpartum mothers.

The results of this study found that all postpartum mothers after doing Oketani massage therapy experienced changes in ASI dam results from the T-test analysis obtained a mean value $=4,800, \mathrm{SD}=$ 1.46 and $\mathrm{p}$ value $=0,000<=0,05$, indicating that Oketani massage therapy effective in changing ASI dams in post partum mothers. Conclusion from this study that the incidence of effective ASI dams can be overcome with Oketani massage.
\end{abstract}

Keywords: Oketani Massage, ASI Dam, Postpartum Mother 


\section{PENDAHULUAN}

Kegagalan dalam proses menyusui sering disebabkan karena timbulnya beberapa masalah. Adapun masalah yang menyebabkan ibu gagal dalam menyusui adalah putting susu lecet, payudara bengkak (bendungan ASI), mastitis dan abses payudara (Sulistyawati,2009). Pemberian ASI ekslusif dipengaruhi oleh beberapa factor antara lain ASI tidak segera keluar, bayi kesulitan dalam mengisap, keadaan putting susu ibu dan promosi susu pengganti ASI (Siregar, 2007).

Menurut Manuaba (2010) bendungan ASI karena penyempitan duktus laktiferus oleh kelenjar-kelenjar yang tidak dikosongkan dengan sempurna atau kelainan pada putting susu. Payudara yang bengkak biasanya terjadi sesudah melahirkan pada hari ketiga atau keempat.

Bendungan ASI merupakan peningkatan aliran vena dari limfe pada payudara dalam ragka mempersiapkan diri untuk proses laktasi, bisa juga karena adanya penyempitan duktus lactiferous pada payudara ibu serta dapat terjadi pula bila memiliki kelainan puting susu seperti putting susu datar dan terbenam (Admin,2007). Bendungan ASI menyebabkan demam, payudara terasa sakit, payudara berwarna merah, payudara bengkak dan payudara mengeras, hal tersebut dapat mempengaruhi proses pemberian ASI (Riskani,2012)

Pijat Oketani merupakan salah satu metode breast care yang tidak menimbulkan rasa nyeri. Pijat oketani dapat menstimulus kekuatan otot pectoralis untuk meningkatkan produksi ASI dan membuat payudara lebih lembut dan elastic. Menurut penelitian yang dilakukan oleh Kabir \& Tasnim (2009) bahwa sebanyak 8 dari 10 sampel yang diteliti menyatakan bahwa pijat oketani $80 \%$ efektif mengatasi masalah payudara diantaranya untuk kelancaran ASI, mencegah bendungan ASI dan putting yang tidak menonjol

Oketani dalam Jeongsug et al (2012) dalam jurnalnya yang berjudul "Effect of Oketani Breast Massage on Breast pain, the Breast milk Ph of Mothers, and the Sucking Speed of Neonates" diperoleh nilai $p<0,001$, yang berarti ada perbedaan setelah dilakukan pijat oketani yaitu seluruh partisipan mengalami peningkatan produksi ASI, perubahan pada putting payudara, dan tidak adanya bendungan ASI setelah diberikan pijat oketani.

Penerapan pijat oketani pada ibu post partum masih jarang dilakukan karena biasanya ibu hanya melakukan pijat payudara biasa. Pijat oketani juga merupakan salah satu metode breast care yang tidak menimbulkan rasa nyeri. Pijat oketani dapat menstimulus kekuatan otot pectoralis untuk meningkatkan produksi ASI dan membuat payudara menjadi lebih lembut dan elastis sehingga meumudahkan bayi untuk mengisap ASI. Di RS Bersalin Masyita belum pernah mendapatkan sosialisasi maupun pelatihan tentang pijat Oketani sehingga perawat dan bidan di ruangan postpartum belum menerapkan pemberian pijat Oketani ini. Pihak rumah sakit masih menggunakan metode pijat payudara konvensional,

Studi pendahuluan yang di lakukan di RS. Bersalin Masyita selama bulan Mei 2018 diproleh jumlah ibu postpartum sebanyak 23 orang mengalami bendungan ASI pada awal minggu setelah kelahiran. Dari latar belakang tersebut, maka perlu dilakukan penelitian untuk mengetahui Efektifitas Pijat Oketani Terhadap bendungan ASI pada ibu Postpartum di RS.Bersalin Masyita

\section{METODE}

Desain penelitian adalah Quasi Experimental dengan rancangan pre dan post test tanpa kelompok kontrol, untuk melihat efektifitas pencegahan terjadinya bendungan ASI pada kelompok intervensi yang dilakukan pijat oketani pijat oketani. di RS.Bersalin Masyita.

\section{HASIL DAN PEMBAHASAN Hasil Penelitian}

1. Analisa Univariat

Tabel 4.1

Distribusi Responden menurut Umur, Pendidikan Pekerjaan, Paritas RSB.Masyita Makassar 


\begin{tabular}{lcc}
\hline \multirow{2}{*}{ Karakteristik Responden } & \multicolumn{2}{c}{ Jumlah } \\
\cline { 2 - 3 } & $\mathrm{n}$ & $\%$ \\
\hline Umur & & \\
$\begin{array}{l}\text { 1.26-35 tahun (dewasa } \\
\text { awal) }\end{array}$ & 11 & 73,3 \\
$\begin{array}{l}\text { 2.36-45 tahun (dewasa } \\
\text { akhir) }\end{array}$ & 4 & 26,7 \\
& & \\
\hline Pendidikan & & \\
1. SD & 2 & 13,3 \\
2.SMP & 3 & 20,0 \\
3.SMA & 7 & 46,7 \\
4.Sarjana & 3 & 20,0 \\
\hline Pekerjaan & & \\
1.Bekerja & 10 & 66,7 \\
2. tidak bekerja & 5 & 33,3 \\
\hline Paritas & & \\
1.Primipara & 7 & 46,7 \\
2.Multipara & 8 & 53,3 \\
\end{tabular}

Tabel 4.1 tentang Karakteristik Ibu post partum, berdasarkan umur menurut WHO usia dewasa awal (26-35 tahun) dan dewasa akhir (36-45 tahun) pada table diatas umur terbanyak yaitu umur dewasa awal yaitu 11 $(73,3 \%)$ ibu post partum . Karakteristik responden pada tingkat pendidikan yakni pendidikan tertinggi pada ibu post partum yaitu tingkat pendidikan SMA sebanyak 7 $(46,7 \%)$ ibu post partum, sedangkan pendidikan terendah yaitu SD sebanyak 2 ibu $(13,3 \%)$ postpartum Karakteristik responden berdasarkan paritas dapat dilihat pada tabel bahwa paritas terbanyak adalah Multi para yaitu sebanyak $8(53,3 \%)$ ibu postpartum dan Primipara sebanyak $7 \quad(46,755 \%)$. Karakteristik yang terakhir adalah pekerjaan dapat dilihat pada tabel diatas bahwa status pekerjaan yang paling banyak adalah ibu bekerja sebanyak $10(66,7 \%)$ ibu post partum yang bekerja.

Tabel 4.2 Distribusi Karakteristik Responden bedungan ASI sebelum pijat Oketani di RSB.Masyita Makassar

\begin{tabular}{|c|c|c|c|}
\hline & Mean & $\mathrm{n}$ & $\begin{array}{l}\text { Std. } \\
\text { Deviatio } \\
\mathrm{n}\end{array}$ \\
\hline $\begin{array}{l}\text { Bendungan } \\
\text { ASI Sebelum } \\
\text { Pijat Oketani }\end{array}$ & 7.73 & 15 & 1.163 \\
\hline
\end{tabular}

Berdasarkan tabel 4.2 didapatkan hasil bahwa bendungan ASI pada ibu postpartum sebelum dilakukan Pijat oketani nilai Mean adalah $=7,73$ dengan $=$ SD 1,163

Tabel 4.3 Distribusi Karakteristik Responden bedungan ASI setelah pijat Oketani di RSB.Masyita Makassar

\begin{tabular}{|c|c|c|c|}
\hline & Mean & $\mathrm{n}$ & $\begin{array}{l}\text { Std. } \\
\text { Deviatio } \\
\mathrm{n}\end{array}$ \\
\hline $\begin{array}{l}\text { Bendungan } \\
\text { ASI Setelah } \\
\text { Pijat Oketani }\end{array}$ & 2.93 & 15 & 1.580 \\
\hline
\end{tabular}

Berdasarkan tabel 4.3 didapatkan hasil bahwa setelah dilakukan Pijat oketani, bendungan ASI yang dialamai oleh ibu postpartum mengalami perubahan yang signifiakan yaitu nilai Mean $=2,93$ dengan $\mathrm{SD}=1,580$

2. Analisis Bivariat

Tabel 4.4 Efektifitas Pijat Oketani Terhadap Bendungan ASI di RSB.Masyita Makassar

\begin{tabular}{lllll}
\hline & Mean & SD & $\mathrm{n}$ & $\begin{array}{l}P \\
\text { value }\end{array}$ \\
\hline $\begin{array}{l}\text { Bendungan } \\
\text { ASI }\end{array}$ & 4,800 & 1,146 & 15 & \\
\hline
\end{tabular}

Berdasarkan tabel 4.4 hasil uji T-test didapatkan ibu post partum setelah dilakukan pijat oketani dengan nilai mean $=4,800, \mathrm{SD}=$ $1,46(p=0,000)$ dengan taraf signifikan $<0,05$ dengan kata lain pemberian terapi pijat oketani efekti dalam mencegah bendungan ASI pada ibu postpartum

\section{PEMBAHASAN}

\section{Bendungan ASI Sebelum Pijat Oketani}

Jumlah Ibu postpartum yang mengalami bendungan ASI pada penelitian ini adalah 15 postpartum, dengan niali mean $=7.73$, SD $=1.580$ sebagian besar ibu postpartum dalam penelitian ini adalah ibu yang usianya dalam kategori dewasa awal menurut WHO yakni 2635 tahun dimana pada usia tersebut ibu postpartum sangat produktif dalam memproduksi penegluaran ASI, apabila ibu post partum tersebut memiliki pengetahuan yang minim tetang bagaimana cara perawatan payudara yang abik dan benar hal ini dapat memicu terjadinya bendungan ASI.

Penelitian ini didukung oleh (Sarwono\&Parmitasari,2008) mengatakan 
bahwa beberapa bendungan ASI disebabkan oleh pengeluaran air susu yang tidak lancar, karena bayi tidak cukup sering menyusu, produksi meningkat, terlambat menyususkan, hubungan dengan bayi (bonding) kurang baik, dan dapat pula karena adanya pembatasan waktu menyusui.

WHO Bendungan ASI terjadi sejak hari ketiga sampai hari keenam setelah persalinan, ketika ASI secara normal dihasilkan, payudara menjadi sangat penuh. Hal in bersifat fisiologis dan dengan pengisapan yang efektif dan pengeluaran ASI oleh bayi, rasa penuh tersebut terisi sangat penuh dengan ASI dan cairan jaringan.

Payudara yang tidak dikosongkan seluruhnya Bila tidak dikeluarkan saat ASI terbentuk, maka volume ASI dalam payudara akan melebihi kapasitas alveoli untuk penyimpanannya sehingga bila situasi saat ini tidak diatasi, maka akan menyebabkan bendungan dan masitis dalam waktu singkat, dan mempengaruhi kelanjutan produksi ASI dalam jangka panjang

\section{Bendungan ASI Setelah Pijat Oketani}

Berdasarkan hasil penelitian setelah dilakukan terapi pijat oketani pada ibu post partum yang mengalami bendungan ASI mengalami perubahan yang signifikan dari nilai mean $=7.73$ menjadi mean $=2.93$. peneliti menyimpulkan bahwa ada perubahan yang signifikan bendungan ASI pada ibu postpartum sebelum dan setelah dilakukan terapi pijat oketani

Penelitian yang dilakukan oleh Kabir \& Tasnim (2009), bahwa sebanyak 8 dari 10 sampel yang diteliti menyatakan bahwa pijat oketani $80 \%$ efektif mengatasi masalah payudara diantaranya untuk kelancaran ASI, mencegah bendungan ASI dan putting yang tidak menonjol .

Jeongsug et al (2012) dalam jurnalnya yang berjudul "Effect of Oketani Breast Massage on Breast pain, the Breast milk Ph of Mothers, and the Sucking Speed of Neonates" diperoleh nilai $p<0,001$, yang berarti ada perbedaan setelah dilakukan pijat oketani yaitu seluruh partisipan mengalami peningkatan produksi ASI, perubahan pada putting payudara, dan tidak adanya bendungan ASI setelah diberikan pijat oketani.

Berdasarkan analisa peneliti bendungan ASI yang dialami oleh ibu postpartum mengalami penurunan yang signifikan setelah dilakukan terapi pijat oketani, hal ini menandakan bahwa terapi pijat oketani dapat Melancarkan ASI pada ibu postpartum. Namun dalam penelitian ini dari 15 responden terdapat 2 responden yang tidak mengalami perubahan bendungan ASI, hal ini dipengaruhi oleh beberapa factor, yang pertama adalah pada saat dilakukan terapi pijat oketani waktu yang digunakan sangat singkat dari waktu yang ditetapkan sesuai dengan SOP terapi pijat oketani, yang kedua adalah pada saat dilakukan terapi pijat oketani bayi ibu terbangun sehingga ibu harus menyusui bayinya terlebih dahulu, yang ketiga adalah ibu postpartum tidak rileks.

\section{Efektifitas Pijat Oketani Terhadap Bendungan ASI}

Pijat oketani merupakan salah satu metode breast care yang tidak menimbulkan rasa nyeri. Pijat oketani dapat menstimulus kekuatan otot pectoralis untuk meningkatkan produksi ASI dan membuat payudara menjadi lebih lembut dan elastis sehingga memudahkan bayi untuk mengisap ASI. Pijat oketani juga akan memberikan rasa lega dan nyaman secara, meningkatkan kualitas ASI, mencegah putting susu lecet dan mastitis serta dapa memperbaiki/ mengurangi masalah laktasi yang disebabkan oleh puting yang rata (flat nipple), putting yang masuk kedalam (inverted) (Machmudah\& Khayati, 2014)

Menurut Tasmin\&Kabir (2009) bahwa tujuan dari pijat oketani adalah meningkatkan kualitas ASI, mencegah putting lecet dan bendungan ASI serta dapat mempebaiki atau mengurangi masalah laktasi yang disebabkan oleh putting yang rata (flat nipple) atau putting susu yang masuk kedalam (inverted). Tanda dan geajalah tersebut merupakan masalah yang menyebabkan ibu mengalami masalah payudara salah satunya bendungan ASI Hasil penelitian menunjukkan bahwa terdapat perbedaan perubahan bendungan ASI sebelum dan sesudah dilakukan terapi pijat oketani hasil uji statistik T-test diperoleh nilai mean $=4,800$, $\mathrm{SD}=1,46 \quad p=0,000<=0,05$ yang berarti terjadi perubahan bendungan ASI pada ibu post partum sebelum setelah dilakukan pijat oketani. Penelitian ini sejalan dengan penelitian yg dilakukan oleh Oketani dalam Jeongsug et al (2012) dalam jurnalnya yang berjudul "Effect of Oketani Breast Massage on Breast pain, the 
Breast milk Ph of Mothers, and the Sucking Speed of Neonates" diperoleh nilai $p<0,001$, yang berarti ada perbedaan setelah dilakukan pijat oketani yaitu seluruh partisipan mengalami peningkatan produksi ASI, perubahan pada putting payudara, dan tidak adanya bendungan ASI setelah diberikan pijat oketani.

Menurut (Saryono,2008) bendungan ASI disebabkan oleh pengeluaran air susu yang tidak lancar, karena bayi tidak cukup sering menyusu, produksi meningkat, terlambat menyususkan, hubungan dengan bayi (bonding) kurang baik, dan dapat pula karena adanya pembatasan waktu menyusui. Selama 24 hingga 48 jam pertama sesudah terlihatnya sekresi lakteal, payudara sering mengalami distensi menjadi keras dan berbenjol-benjol. Keadaan ini yang disebut dengan bendungan air susu atau "caked breast", sering menyebabkan rasa nyeri yang cukup hebat dan bisa disertai dengan kenaikan suhu. Kelainan tersebut meggambarkan aliran darah vena normal yang berlebihan dan penggembungan limfatik dalam payudara, yang merupakan prekusor regular untuk terjadinya laktasi.

Pijat oketani merupakan manajemen keterampilan untuk mengatasi masalah laktasi seperti produksi ASI yang tidak cukup, pembengkakan payudara, pijat oketani akan menyebabkan payudara menjadi lunak, lentur dan areola akan menjadi elastis, duktus lactiferous dan putting susu juga menjadi elastis. Seluruh payudara menjadi lentur dan menghasilkan ASI berkualitas baik karena kandungan total solids, konsentrasi lemak dan gross energy meningkat (Machmudah,dkk 2014)

Berdasarkan analisis peneliti bahwa terapi pijat oketani efektif dalam perubahan bendungan ASI dan dapat mencegah bendungan ASI pada ibu postpartum.

\section{KESIMPULAN}

Sebelum dilakukan Pijat oketani nilai Mean adalah 7,73 dengan SD 1, 1632.

1. Setelah dilakukan Pijat oketani, bendungan ASI yang dialamai oleh ibu postpartum mengalami perubahan yang signifiakan yaitu nilai Mean 2,93 dengan SD 1,580

2. pijat oketani efektif dalam perubahan Bendungan ASI pada ibu postpartum dengan nilai $\rho$.Value 0.0

\section{REFERENSI}

1. Admin, H.2007. Konsep Penanganan ASI Eksklusif. Jakarta: EGC

2. Jeongsug., Hye Young., Sukhee \& Myeong Soo. (2012). Effects of Oketani Breast Massage on Breast Pain, the Breast Milk pH of Mothers and The Sucking Speed of Neonates. Journal of Korean J Women Health Nurs, Vol 18 No 2, 149-158

3. Kabir \& Tasnim. (2009). Oketani Lactation Management : A New Method to Augment Breast Milk. Journal of Bangladesh College of Physicians and Surgeon, Vol. 27,No 3

4. Machmudah,dkk.(2014). Pijat oketani dan Oksitosin terhadap parameter produksi ASI Pada ibu Post Secsio Sesarea http://www.journal.stikesmuhpkj.ac.id/journal/ index.phd/jik/article/download/26/2

5. Manuaba,IBG., 2010. Ilmu Kebidanan, Penyakit Kandungan dan KB untuk Pendidikan Bidan Edisi 2. Jakarta:EGC

6. Riksani, R.2012. Keajaiban ASI Eksklusif. Jakarta: Dunia Sehat

7. Sarwono dan Parmitasari. 2008. Perawatan Payudara Dilengkapi dengan Deteksi Dini Terhadap Penyakit Payudara. Jogjakarta: Mitra Cendikia Press

8. Siregar, M Arifin. (2007). Faktor-Faktor yang Mempengaruhi Pemberian ASI oleh $\mathrm{Ibu}$ Melahirkan. http://library.usu.ac.id/download/fkm/fkmarifin.pdf. Diakses tanggal 20 Desember 2018 